\title{
Essay
}

\section{Putting PhDs to Work: Career Planning for Today's Scientist}

\author{
Jennifer A. Hobin, ${ }^{*}$ Philip S. Clifford, ${ }^{\dagger}$ Ben M. Dunn, ${ }^{\ddagger}$ Susan Rich, $\$$ \\ and Louis B. Justement ${ }^{\|}$
}

\begin{abstract}
*American Association for Cancer Research, Washington, DC 20005; ${ }^{\dagger}$ Graduate School of Biomedical Sciences and Departments of Anesthesiology and Physiology, Medical College of Wisconsin, Milwaukee, WI 53295; ‡Department of Biochemistry and Molecular Biology, University of Florida, Gainesville, FL 32610-0245; $\S^{\S}$ Department of Life Sciences, Graduate School, University of Alabama at Birmingham, Birmingham, AL 35294; "Medical Scientist Training Program and Department of Microbiology, University of Alabama at Birmingham, Birmingham, AL 35294
\end{abstract}

Submitted April 24, 2013; Revised September 24, 2013; Accepted September 30, 2013

Monitoring Editor: Diane Ebert-May

\begin{abstract}
Individual development plans (IDPs) have been promoted nationally as a tool to help research trainees explore career opportunities and set career goals. Despite the interest in IDPs from a policy perspective, there is little information about how they have been used. The authors examined IDP awareness and use, the benefits of creating an IDP, and ways to facilitate its use by administering a survey to current or former postdoctoral researchers via the National Postdoctoral Association (NPA) and University of Alabama at Birmingham email lists; individuals belonging to Federation of American Societies for Experimental Biology member societies who mentored postdocs; and postdoctoral administrators at member institutions of the Association of American Medical Colleges and the NPA. Although most postdoctoral administrators $(>80 \%)$ were familiar with IDPs, less than $50 \%$ of postdocs and only $20 \%$ of mentors were aware of IDPs. For those postdocs and mentors who reported creating an IDP, the process helped postdocs to identify the skills and abilities necessary for career success and facilitated communication between postdocs and their mentors. Despite the fact that creating an IDP benefits postdocs and mentors, IDP use will likely remain low unless institutions and research mentors encourage trainees to engage in this process.
\end{abstract}

\section{INTRODUCTION}

Graduatetraining programs in the sciences have historically focused on training individuals in an apprenticeship mode. Graduate students and postdoctoral researchers were afforded the opportunity to specialize in the discipline of their mentor and to develop the scientific acumen and the technical skills needed to pursue an academic, research-focused position in that discipline. Although this has always been

DOI: $10.1187 /$ cbe-13-04-0085

Address correspondence to: Jennifer A. Hobin (jhobin@gmail.com).

(C) 2014 J. A. Hobin et al. CBE-Life Sciences Education (C) 2014 The American Society for Cell Biology. This article is distributed by The American Society for Cell Biology under license from the author(s). It is available to the public under an AttributionNoncommercial-Share Alike 3.0 Unported Creative Commons License (http:/ / creativecommons.org/licenses/by-nc-sa/3.0).

"ASCB ${ }^{\circledR}$ " and "The American Society for Cell Biology ${ }^{\mathbb{R} \text { " }}$ are registered trademarks of The American Society for Cell Biology. a demanding endeavor, the challenges have become more acute with the flattening of federal research funding (American Association for the Advancement of Science, 2012), the increase in the number of doctoral scientists in the United States and abroad (National Science Foundation [NSF], 2012a), and the decline in the proportion of scientists holding tenured or tenure-track positions in academia (NSF, 2012b).

\section{The Benefits of Career and Professional Development Planning}

Devotinggreater attention to career planning with a focus on setting clear, attainable goals will undoubtedly help trainees meet the challenges of today's highly competitive job market. Goal setting has a positive impact on performance and career outcomes (Locke and Latham, 2002). Simply imagining future goals motivates us to pursue them (Ajzen, 1991), and we are more likely to reach our goals when we develop specific plans for pursuing them-deciding when, where, and how to take the necessary steps (Gollwitzer, 1999). 
People who develop and implement strategies to pursue career-specific goals achieve greater career success as measured by salary, promotions, and level of responsibility. They also report greater career satisfaction and consider themselves more successful than do their peers without career plans (Ng et al., 2005; Abele and Wiese, 2008). Postdocs who developed training plans with their advisors at the start of their appointments published more papers,reported greater satisfaction with their postdoctoral experience, gave their advisors higher ratings, and experienced fewer conflicts with their advisors compared with postdocs who had not developed plans (Davis, 2006).

\section{Creating an Individual Development Plan}

To assist trainees in the sciences with career planning, the Federation of American Societies for Experimental Biology (FASEB) promulgated the idea of an individual development plan (IDP) for postdoctoral fellows (FASEB, 2002). The IDP outlines a career-planning process designed to help postdocs identify career goals and develop a plan for meeting those goals. Constructing an IDP is an iterative process (Clifford, 2002) that involves assessing one's career skills, values, and interests; exploring job opportunities and determining which career is the best fit for one's skills, interests, and values; and developing a realistic set of goals to help prepare for that career.

Since FASEB introduced the IDP, it has received considerable attention in the research training community: the National Postdoctoral Association (NPA) recommends developing an IDP as a best practice for postdoctoral scholars (NPA, 2011), training institutions and professional societies have offered IDP workshops to their trainees, and the National Institute of General Medical Sciences (NIGMS, 2011) and the National Institutes of Health (NIH, 2013) recommended that graduate students and postdocs create an IDP.

\section{IDPs in Practice}

In spite of significant interest in IDPs, there is a dearth of information about how widespread awareness of IDPs is and how the resource has been used. To address this information gap, FASEB administered surveys (see Supplemental Material) to postdoctoral office administrators, postdoctoral researchers, and current and former mentors of postdocs. Fifty-seven people responded to the postdoctoral administrator survey. This group consisted of postdoctoral affairs office staff $(45.8 \%)$, deans of postdoctoral affairs $(31 \%)$, other institutional officials responsible for postdoctoral affairs $(15 \%)$, postdoctoral association leaders (3\%), and a group titled "other" $(5.1 \%)$ that included a director of professional development and an assistant dean of graduate education. Two hundred and sixty people responded to the postdoctoral survey, including 233 current postdocs and 27 former postdocs; 337 mentors responded to the mentor survey.

Postdoctoral office administrators and staff were the most familiar with the IDP (Figure 1). Eighty-eight percent had heard of IDPs, $65 \%$ indicated that their institutions recommended that postdocs develop an IDP, and $8 \%$ required their postdocs to do so. Most postdocs and mentors, on the other hand, had never heard of the IDP. Only $43 \%$ of postdoc re-

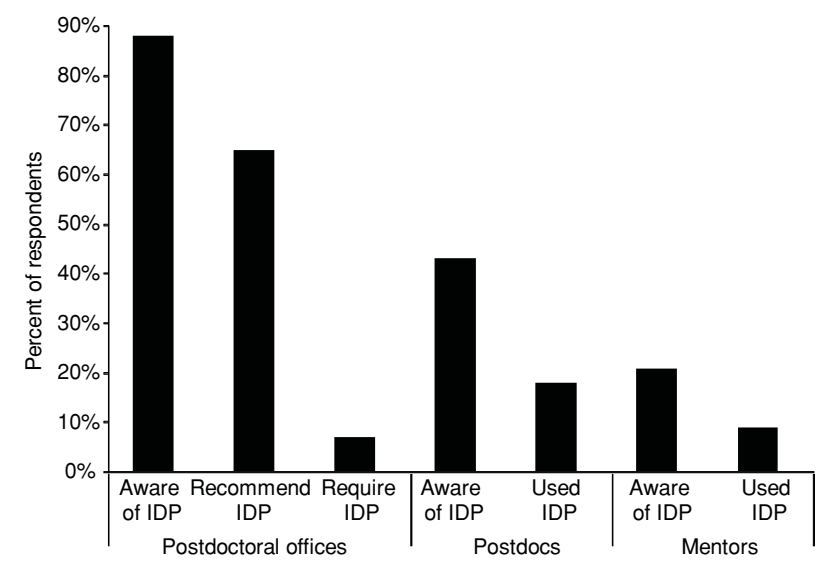

Figure 1. IDP use and awareness. Many postdoctoral administrators are aware of the IDP, but fewer recommend or require that postdocs develop one. Less than half of postdocs who were aware of the IDP created one, and less than half of mentors who were aware of the IDP helped their postdocs to create one.

spondents and a mere $20 \%$ of mentors surveyed were familiar with the process.

Lack of awareness only partially accounts for the failure of trainees and their mentors to develop career and professional development plans, however. Only $43 \%$ of the postdocs and $43 \%$ of mentors who knew about IDPs had actually started the process, equal to $19 \%$ of all postdocs and $9 \%$ of all mentors we surveyed, and many of the postdocs who began an IDP did not complete it. Although 92\% conducted a self-assessment, only $79 \%$ surveyed career opportunities, and even fewer discussed their IDPs with their mentors (58\%). The primary reason postdocs did not develop an IDP was simple: they were not required to do so $(45 \%)$. They also indicated that they did not know how to conduct a self-assessment (19\%), did not have or know where to find career information (9\%), had already decided on a career $(14 \%)$, or simply did not have the time $(16 \%)$. Twenty percent of postdocs were uncomfortable giving feedback to or receiving feedback from their mentors $(20 \%)$, and open-ended responses to questions inquiring why postdocs did not complete an IDP or discuss their IDPs with their mentors revealed that some postdocs thought their mentors were not interested in the IDP concept, thought their mentors were unwilling to assist them with the process, or thought faculty discouraged them from completing an IDP. These responses, although anecdotal, suggest that greater receptivity to IDPs on the part of mentors could facilitate IDP completion by trainees, although additional data are necessary to test this possibility.

Our data reveal a disconnect between trainees and their advisors when it comes to career conversations. Although many postdocs were reluctant to discuss their career plans with their principal investigators, most mentors reported that they had assisted or were willing to assist their postdocs in this regard. Indeed, among mentors who had not helped their trainees develop an IDP per se, 75\% helped them to develop some kind of career or professional development plan, although only $5 \%$ helped their postdocs develop a written plan. The majority $(71 \%)$ of mentors who did not work on a career plan with their postdocs reported that they would be willing to help them create a written plan. Still, what accounts for 


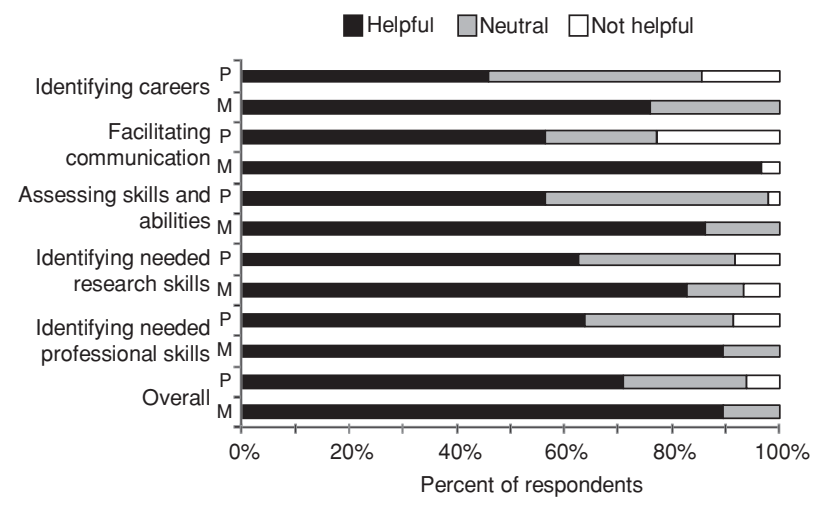

Figure 2. Postdocs $(\mathrm{P})$ were asked to rate how helpful the IDP process was overall and for various aspects of their career and professional development. Mentors (M) were asked to rate how helpful the IDP process was overall and for various aspects of their trainees' careers and professional development. Ratings were on scale of 1-5, wherein 1 was "not at all helpful" and 5 was "very helpful." Scores of 1 and 2 were considered "not helpful," a score of 3 was considered "neutral," and scores of 4 and 5 were considered "helpful."

the many mentors who had not developed any type of career plan with their postdocs? The primary reason mentors cited for not helping their postdocs develop an IDP or some other type of career plan was that their postdocs had not asked for help (65\%). Many mentors reported they were not required to develop a career plan with their trainees $(36 \%)$ or that it was not necessary, because their postdocs had already decided on a career $(28 \%)$. A lack of information about career options $(8 \%)$ and the skills needed for those careers $(9 \%)$ were also factors for some.

Bothpostdocs (71\%) and mentors (90\%) who worked on an IDP found the process to be valuable overall (Figure 2). They reported that it helped postdocs to assess their skills and abilities (postdocs: 56\%; mentors: $86 \%$ ), helped postdocs assess the research skills (postdocs: 63\%; mentors: $83 \%$ ) and additional skills or abilities (postdocs: $64 \%$; mentors: $90 \%$ ) they would need to succeed in their careers, and facilitated communication between postdocs and their mentors about career goals (postdocs: 56\%; mentors: 97\%).

Although we did not examine the impact of creating an IDP on postdoctoral performance or goal attainment, the IDP process is consistent with best practices that have emerged from decades of research on the impact of goal setting on performance (Seijts and Latham, 2012). Goals affect performance by directing attention to goal-relevant activities, energizing people toward greater effort, and helping them persist in that effort (Locke and Latham, 2002). With its focus on skills development, the IDP process emphasizes setting learning goals rather than performance goals. Learning goals focus an individual's attention on the process of discovering how to perform a task correctly, such as learning how to write scientific publications, rather than on specific performance metrics, such as publishing a certain number of papers per year. Learning goals motivate better performance in individuals who do not yet have the knowledge or established behavioral routines necessary to perform a particular task (Latham et al., 2008), which is arguably the case for most research trainees, who are still novices at many of the skills needed to succeed in science. Such goals lead these individuals to systematically search for new ideas, to exert effort to actively seek feedback, and to be reflective.

Research also shows that individuals are more likely to achieve their goals if they are involved in setting them. One study found that scientists and engineers who were allowed to participate in goal setting performed significantly better than their counterparts who were assigned goals by their managers (Latham et al., 1978). People persist in expending effort toward goals if there is a relationship between what they are doing and outcomes that are important to them (Latham and Locke, 2007). The goal of an IDP is to develop an "individualized" career and professional development plan based on one's unique skills, interests, and values. Trainees are at the center of this process and responsible for setting their own goals.

As we noted above, research also shows that individuals are more likely to perform at a higher level if they set specific rather than general goals (Gollwitzer, 1999). FASEB's IDP recommended that trainees "define the approaches to obtain the specific skills and strengths" they want to obtain and to set a time frame for obtaining them. A new, interactive Web-based IDP called myIDP (myIDP, 2012) goes even further by helping users to set specific, measurable, action-oriented, realistic, and time-bound (SMART) goals and to develop a plan to ensure they are accountable for meeting those goals. myIDP also recommends that trainees break their goals into subparts so as not to become overwhelmed by the complexity of a given goal, another practice found to be important for accomplishing goals that are likely to take a long time to complete (Seijts and Latham, 2012), as is the case for many research-related goals, such as developing new technical skills, carrying out research projects, and writing grant applications and research papers.

Implicit in the IDP process is the notion that goals should be written down. Only 5\% of mentors we surveyed helped their trainees create a written plan. The literature shows that people are more likely to pursue their goals if they record where and when they will accomplish specific behaviors (Gollwitzer, 1999; Brown et al., 2003).

Although the responsibility for creating an IDP ultimately lies with each graduate student and postdoc, trainees are strongly encouraged to solicit feedback from their mentors. In fact, FASEB recommended that mentors meet with trainees on an annual basis to review progress and revise plans as necessary. Research shows that obtaining feedback is important for goal achievement, as it helps individuals to gauge their progress and determine whether a change of strategy is necessary (Latham et al., 2008). Moreover, when individuals receive feedback that they have achieved a proximal goal (e.g., developing a new technical skill), it signals that they are making progress toward a distal goal (e.g., obtaining a position conducting cutting-edge research), thereby sustaining their effort toward that goal (Latham and Seijts, 1999).

\section{Facilitating the Development of IDPs}

Our data show that simply making postdocs and their mentors aware of IDPs will not ensure that they will create one. However, the trainees we surveyed reported that having information about career opportunities for scientists $(87 \%)$, the skills and abilities needed to pursue those careers $(89 \%)$, self-assessment tools (82\%) and workshops (72.5\%), career 
exploration and planning workshops (88\%), and professional development resources (88\%) would make it easier to complete an IDP. It follows, then, that providing access to these resources in the context of a framework for creating an IDP could make trainees more likely to engage in this process. The myIDP tool does just that. Unlike FASEB's original IDP, which only outlines the planning process, myIDP provides tools to help users assess their career-related skills, interests, and values; identify and explore possible career paths based on their assessments; and set realistic career goals.

Although pressure from federal funding organizations and the availability of IDP resources is likely to increase IDP awareness, we fear that engagement in a deliberate career exploration and goal-setting process will remain low unless research training institutions and, most importantly, mentors support and encourage the use of IDPs. Indeed, research demonstrates that support from key decision leaders is important for motivating goal achievement and improving performance (Seijts and Latham, 2012), and we believe it will be important for promoting use of IDPs. Therefore, we offer the following recommendations for increasing IDP awareness and use.

\section{Recommendations for Postdocs}

- Recognize that the responsibility for exploring career options and developing a career plan lies with you.

- Begin career exploration and develop an IDP early in your appointment.

- Meet with career advisors and postdoctoral office staff to discuss what resources are available to you.

- Do not be afraid to discuss your career plans with your mentors.

- Remember that the IDP process is valuable, even if you have already decided on a career and even if you are pursuing a career in academic research.

- Do not expect to complete this process in a day, a week, or even a month. Career planning takes time; it should be an iterative process during which you periodically reassess your goals.

\section{Recommendations for Mentors}

- Talk to trainees about career planning early in the postdoctoral appointment. Consider using the Association of American Medical Colleges (AAMC) Compact between Postdoctoral Appointees and Their Mentors to guide this discussion (AAMC, 2006).

- Familiarize yourself with the career-planning resources offered by your institution and scientific societies, so that you can direct trainees to those resources.

- Encourage trainees to participate in career and professional development programs offered through your institution, scientific meetings, and professional societies.

- Focus on helping trainees identify goals that promote the development of knowledge and skills that will enable them to achieve their long-term career goals.

\section{Recommendations for Postdoctoral Training Offices}

- Provide information about IDPs and career planning directly to postdocs and mentors through workshops, sem- inars, and email announcements. Do not simply post this information on a website.

- Send annual reminders that postdocs and mentors should develop or update the IDPs.

- Consider ways to integrate IDPs into your training program, such as by developing an IDP course or requiring completion of the IDP as part of the appointment process.

- Convey to mentors that postdocs want assistance with their career planning.

- Remind mentors that creating an IDP is valuable for postdocs and themselves, and encourage them to integrate the IDP into their training activities.

- Remind mentors and trainees that the IDP process is designed to set goals that will facilitate acquisition of knowledge and skills to enhance an individual's ability to achieve long-term career success, as opposed to being a tool for performance review.

\section{DEVELOPING A NEW PARADIGM IN TRAINING}

Going forward, it will be important to develop a culture in which creating an individualized training and career development plan is an accepted practice for trainees, faculty, and institutions. The benefits are potentially significant. Creating an IDP will help postdocs prioritize their research and training goals, increase their research productivity while they are training, and enhance their awareness of and success in competing for a wider range of career paths. For faculty, the benefits include more productive and harmonious labs, improved chances of obtaining funding from agencies that take training into consideration during review, and the recognition that comes through the successes of trainees. We also believe that this process could be beneficial to the enterprise overall. Providing guidance and resources to help trainees identify rewarding and stable positions that utilize their scientific training and fulfill their career aspirations could encourage continued interest in biomedical research training, thereby ensuring a constant supply of research talent.

\section{REFERENCES}

Abele AE, Wiese BS (2008). The nomological network of selfmanagement strategies and career success. J Occup Organ Psychol 81, 733-749.

Ajzen I (1991). The theory of planned behavior. Org Behav Hum Decis Process 50, 179-211.

American Association for the Advancement of Science (2012). AAAS Report XXXVI: Research and Development, Washington, DC.

Association of American Medical Colleges (2006). Compact between Postdoctoral Appointees and Their Mentors, Washington, DC.

Brown SD, Krane NER, Brecheisen J, Castelino P, Budisin I, Miller $\mathrm{M}$, Edens L (2003). Critical ingredients of career choice interventions: more analyses and new hypotheses. J Vocat Behav 62, 411-428.

Clifford PS (2002). Quality time with your mentor. Scientist 16, 59.

Davis G (2006). Improving the postdoctoral experience: an empirical approach. In: The Science and Engineering Workforce in the United States, ed. R Freeman and D Groff, Chicago: University of Chicago Press.

Federation of American Societies for Experimental Biology (2002). Individual Development Plan for Postdoctoral Fellows, Bethesda, MD. 
Gollwitzer PM (1999). Implementation intentions: strong effects of simple plans. Am Psychol 54, 493-503.

Latham GP, Borgnoni L, Petitta L (2008). Goal setting and performance management in the public sector. Int Public Management J 11, 385-403.

Latham GP, Locke EA (2007). New developments in and directions for goal-setting research. Eur Psychol 12, 290-300.

Latham GP, Mitchell TR, Dossett DL (1978). The importance of participative goal setting and anticipated rewards on goal difficulty and job performance. J Appl Psychol 63, 163-171.

Latham GP, Seijts GH (1999). The effects of proximal and distal goals on performance on a moderately complex task. J Org Behav 20, 421429.

Locke AE, Latham GP (2002). Building a practically useful theory of goal setting and task motivation: a 35-year odyssey. Am Psychol 57, 705-717.

myIDP (2012). myIDP Home Page. http:/ / myidp.sciencecareers.org (accessed 21 April 2013).
National Institute of General Medical Sciences (2011). Investing in the Future: NIGMS Strategic Plan for Biomedical and Behavioral Research Training 2011, Bethesda, MD.

National Institutes of Health (2013). NIH Encourages Institutions to Develop Individual Development Plans for Graduate Students and Postdoctoral Researchers, Notice Number NOT-OD-13-093, Bethesda, MD

National Postdoctoral Association (2011). Recommendations for Postdoctoral Policies and Practices, Washington, DC.

National Science Foundation (NSF) (2012a). Science and Engineering Indicators 2012, Arlington, VA, pp. 2-1-2-42.

NSF (2012b). Science and Engineering Indicators 2012, Arlington, VA, pp. 3-1-3-65.

Ng TWH, Eby LT, Sorensen KL, Feldman DC (2005). Predictors of objective and subjective career success: a meta-analysis. Personnel Psychol 58, 367-408.

Seijts GH, Latham GP (2012). Knowing when to set learning versus performance goals. Organ Dyn 41, 1-6. 